\title{
ANDROGENIZATION OF THE FEMALE RAT WITH ANDROSTENEDIOL
}

\author{
D. C. JOHNSON \\ Departments of Obstetrics and Gynecology and Physiology, \\ University of Kansas Medical Center, Kansas City, Kansas
}

\section{(Received 14th August 1972)}

The induction of a persistent vaginal cornification-anovulatory syndrome (androgenization) following steroid treatment of the neonatal female rat has been well documented (reviewed by Johnson, 1972). The exact timing of a 'critical period' for the induction of this syndrome has not been determined but, in males, the gonads must be removed within $48 \mathrm{hr}$ of birth in order to prevent their effects upon the hypothalamic-hypophysial axis. The upper limit in time for androgen to have any permanent effects is generally considered to be Day 10 . While early (Days 1 to 3 ) postnatal treatment with testosterone can seriously interfere with normal vaginal development, this is clearly the most efficient time for induction of androgenization (Alklint \& Norgren, 1971). Nearly all comparative studies involving a variety of steroids have used Day 5 for treatment, however, since this is a convenient, though not necessarily optimal, time.

Testosterone is considered the most potent androgenizing agent but androstenedione is also very effective when treatment is started soon after birth; 100 $\mu \mathrm{g}$ on each of 4 days produces $100 \%$ anovulatory animals (Luttge \& Whalen, 1970). By contrast, the saturated A-ring androgens, such as dihydrotestosterone and 5a-androstan-3a,17b-diol, appear to be ineffective. The latter compound has not been adequately tested, but even large doses of dihydrotestosterone are without effect (Luttge \& Whalen, 1970). These compounds can, however, be more potent than testosterone in virilizing the embryonic duct systems in male and female rats (Goldman \& Baker, 1971).

The $\Delta^{5} \mathrm{c}-19$ androgens, which are produced by testes, ovaries and adrenals, have not received attention in the study of androgenization. These compounds are considered to be relatively weak androgens but they do cause virilization (Josso, 1970). Increased production of these androgens follows treatment of animals with inhibitors of $\Delta^{5}$-3b-ol-steroid dehydrogenase (SDH) and $\Delta^{-4-5}$ isomerase (literature reviewed by Bongiovanni, Eberlein, Goldman \& New, 1967). While such treatment produces an experimental adrenogenital syndrome with virilization, reproductive performance has not been recorded.

In a preliminary study, nine out of ten 5-day-old females treated with $1 \mathrm{mg}$ testosterone, as an aqueous suspension, had CL in their ovaries at 90 days of age. None of the nine females treated with $1 \mathrm{mg} \Delta^{4}$ androstenedione were anovulatory, but four out of six females treated with $1 \mathrm{mg} \Delta^{5}$ androstenediol were without CL at 90 days of age. These results suggested that the latter steroid should be investigated as a possible androgenizing agent. 
Pregnant females of the Holtzman strain were obtained on the 15th day after finding spermatozoa in the vagina. They were maintained in temperatureand light- (14 hr light/day) controlled quarters with free access to Purina laboratory chow and tap water. At the time of parturition (designated Day 1), all litters were reduced to eight young. Some females were injected subcutaneously with $\Delta^{5}$-androstene-3b-ol-17b-propionate, dissolved in $0.05 \mathrm{ml}$ sesame oil, on the day of parturition, some about $96 \mathrm{hr}$ later, and some at both times. Controls received the sesame oil only.

In the first series, the animals were killed when they were 60 days old. All of the females injected (single dose) with $25 \mu \mathrm{g}$ (nineteen) or $50 \mu \mathrm{g}$ (twenty-one) at $96 \mathrm{hr}$ had ovaries containing several sets of CL, i.e. indistinguishable from those of oil-treated controls. Four of twenty-four (16.7\%) females that received $250 \mu \mathrm{g}$ were anovulatory. In a second series, fourteen females were injected with $250 \mu \mathrm{g}$ on Day 1. Laparotomy under ether anaesthesia on Day 48 revealed that only one animal had CL $(93 \%$ anovulatory). When re-examined at 70 days, all animals lacked CL. The mean ovarian weight for four animals killed at this time was $28 \cdot 1 \pm 3.2 \mathrm{mg}$; that for fifteen controls was $56.5 \pm 1.3 \mathrm{mg}$. When treated with $250 \mu \mathrm{g}$ on Day 1 and another $250 \mu \mathrm{g}$ on Day 5, all of the females (twenty) were anovulatory on Day 48. The mean ovarian weight on Day 70 for this group was $34.9 \pm 1.5 \mathrm{mg}$ (four females). All eleven animals that received $50 \mu \mathrm{g}$ on Day 1 and $250 \mu \mathrm{g}$ on Day 5 were also anovulatory on Day 48. Of a group treated with $50 \mu \mathrm{g}$ on Day 1 , and $50 \mu \mathrm{g}$ on Day 5 , only five rats survived. When this group was 48 days old, three of the animals lacked CL (60\% anovulatory). Vaginal smears indicated that three animals were in constant vaginal oestrus and the two with CL were cyclic; three complete cycles were recorded. Laparotomy at 14 weeks of age revealed that only one animal in the group had fresh CL and at autopsy, when 6 months old, all animals had become anovulatory. The mean ovarian weight at this time was $44 \cdot 1 \pm 1 \cdot 3 \mathrm{mg}$.

Serum FSH and LH were measured in fifteen animals (five each from the groups receiving $250 \mu \mathrm{g}$ on Day $1,250 \mu \mathrm{g}$ on Days 1 and 5 and $50 \mu \mathrm{g}$ on Day 1 and $250 \mu \mathrm{g}$ on Day 5) using radioimmunoassay kits supplied by the NIAMD. Rat Pituitary Program. Since there were no differences between groups, the results were pooled. The mean serum $\mathrm{LH}$ concentration was $47 \cdot 0 \pm 7 \cdot 4 \mathrm{ng} / \mathrm{ml}$ (RP-1 $=0.03 \times$ NIH-LH-S1 by ovarian ascorbic acid assay) on Day $70 ;$ FSH was $243 \pm 26 \mathrm{ng} / \mathrm{ml}$ (RP-1 =2.1 $\times$ NIH-FSH-S1 by Steelman-Pohley assay). For comparison, sera from ten females androgenized with $50 \mu \mathrm{g}$ TP on Day 5 and bled at the same time were measured; the mean LH concentration was 52.8 $\pm 4.0 \mathrm{ng} / \mathrm{ml}$ and that of FSH was $209 \pm 8.5 \mathrm{ng} / \mathrm{ml}$. The mean values for twentyfive normal females of the same age killed at various stages of the oestrous cycle, but excluding animals in late pro-oestrous and early oestrus, were: LH $46 \cdot 3 \pm 1 \cdot 2$ $\mathrm{ng} / \mathrm{ml}$ and FSH $230 \pm 9 \mathrm{ng} / \mathrm{ml}$. Obviously the androgenization did not cause an increase, or decrease, in the average level of FSH or LH.

The results of these experiments clearly demonstrate that a $\Delta^{5}$ androgen can androgenize the hypothalamic-hypophysial axis of the female rat. While the minimal effective dose was not determined, huge doses do not appear to be necessary; all of the animals treated with $50 \mu \mathrm{g}$ on Day 1 and Day 5 became anovulatory. Furthermore, the $50-\mu \mathrm{g}$ dose on Day 1 appeared to prime the 
system so that $250 \mu \mathrm{g}$ on Day 5 was effective in $100 \%$ rather than $16.7 \%$ of the animals.

Certainly, $\Delta^{5}$ androstenediol is not unique in causing androgenization of the hypothalamus. A great variety of compounds, including oestrogens and antioestrogens, have this ability. The physiological significance of these findings appears particularly relevant to situations where increased production of $\Delta^{5}$ androgens could occur. Perhaps the most obvious condition is that resulting from lack of SDH activity (Bongiovanni $e$ t al., 1967). This could occur through a genetic defect in enzyme production mechanisms or chemical inhibition of production and/or activity. A large number of compounds have been implicated in the latter action. Gellert, Bakke \& Lawrence (1971) have discussed the seeming paradox of masculinizing female rats by the administration of oestrogen. Induction of an adrenogenital syndrome by oestrogen, with embryonic masculinization, has been known for many years (Witschi, 1953). Since oestrogens have been shown to inhibit production and activity of SDH, as well as to induce adrenal enlargement and virilization of fetuses, this might account for much of their masculinizing and androgenizing activity, i.e. through increased output of $\Delta^{5}$-androgens from the adrenals. The same mechanism could be applied to any compound that interfered with normal steroidogenesis by inhibiting SDH. Other effects of administered steroids, particularly those on the central nervous system, cannot be ignored. For example, oestrogens are known to increase adrenal size and stimulate steroidogenesis by central stimulation of ACTH output (see discussion by Biogiovanni et al., 1967).

The research described in this paper was supported in part by a grant from the Population Council Inc. The gift of radioimmunoassay kits by the National Institute of Arthritis and Metabolic Diseases is gratefully acknowledged.

\section{REFERENCES}

Alkint, T. \& Norgren, A. (1971) Effects of neonatally injected non-esterified testosterone on reproductive function in female rats. Acta endocr., Copenh. 66, 720.

Bongiovanni, A. M., Eberlein, W. R., Goldman, A. S. \& New, M. (1967) Disorders of adrenal steroid biogenesis. Recent Prog. Horm. Res. 23, 375.

Gellert, R. J., Bakke, J. L. \& LaWrence, N. L. (1971) Persistent estrus and altered estrogen sensitivity in rats treated neonatally with clomiphene citrate. Fert. Steril. 22, 244.

Goldman, A. S. \& Baker, M. K. (1971) Androgenicity in the rat fetus of metabolites of testosterone and antagonism by cyproterone acetate. Endocrinology, 89, 276.

Johnson, D. C. (1972) Sexual differentiation of gonadotrophin patterns. Am. Zool. 12, 193.

Josso, N. (1970) Effect of cyanoketone, an inhibitor of $\Delta 5-3 b$-hydroxysteroid dehydrogenase, on the reproductive tracts of male fetal rats, in organ culture. Biol. Reprod. $2,85$.

LUTTGE, W. G. \& WhaLEN, R. E. (1970) Dihydrotestosterone, androstenedione, testosterone; comparative effectiveness in masculinizing and defeminizing reproductive systems in male and female rats. Horm. E Behav. 1, 265.

Wrтschi, E. (1953) The experimental adrenogenital syndrome in the frog. F. clin. Endocr. Metab. 13, 316. 